\title{
Analysis of Anti HBs Titres in Health Care Workers of Clinical Laboratory at RL Jalappa Hospital
}

\author{
Parimala Subramani*, Anitha Deva and Beena Parvangada Madappa \\ Department of Microbiology, Sri Devaraj Urs Academy of Higher Education and Research, Tamaka, \\ Kolar - 563 101, India.
}

\begin{abstract}
A retrospective analysis of antiHbs titres among health care personnel working in clinical laboratory which includes Microbiology, Pathology, Biochemistry and phlebotomy will be done. The data obtained following blood collection and ELISA for quantitation of their antibody titers was analyzed. A total of 56 samples were collected. Antibiotics titers were measured by ELISA. Titers of $10 \mathrm{mIU} / \mathrm{ml}$ was considered protective. Out of the 56 samples collected, 50(90.9\%) had antibody titers more than $10 \mathrm{mlU} / \mathrm{ml}$. $\mathbf{1 1}(\mathbf{1 9 . 5 6 \% )}$ ) of them were not immunized against Hepatitis $B$.
\end{abstract}

Keywords: Anti HBs, Health Care, Clinical Labs, Jalappa Hospital.

\footnotetext{
*Correspondence: mjchand@gmail.com; 9740189773
}

(Received: 03 April 2019; accepted: 20 May 2019)

Citation: Parimala Subramani, Anitha Deva and Beena Parvangada Madappa, Analysis of Anti HBs Titres in Health Care Workers of Clinical Laboratory at RL Jalappa Hospital, J Pure Appl Microbiol., 2019; 13(2): 1223-1226. doi: 10.22207/JPAM.13.2.63

C The Author(s) 2019. Open Access. This article is distributed under the terms of the Creative Commons Attribution 4.0 International License which permits unrestricted use, sharing, distribution, and reproduction in any medium, provided you give appropriate credit to the original author(s) and the source, provide a link to the Creative Commons license, and indicate if changes were made. 


\section{INTRODUCTION}

Hepatitis B infection is a serious public health problem world wide resulting in cirrhosis and hepatocellular cancer. Health care workers are vulnerable to laboratory acquired infection like hepatitis B, Human immunodeficiency virus (HIV), Hepatitis C Virus(HCV) ${ }^{1,2}$. Laboratory acquired infections are defined as all infections acquired through laboratory or lab related activities. In this process contact with blood and body fluids due to accidental exposure are at a higher risk of developing infections. It is found that transmission of hepatitis b infection is 100 times more than HIV with needle stick injuries ${ }^{3}$. Hepatitis B infection can be prevented by vaccination to hepatitis $b$ surface antigen. Antibodies to hepatitis $B$ surface antigen are protective antibodies against HBV Infection

The protective cut off level of antibodies to Hepatitis B surface antigen was set at $10 \mathrm{mIU} /$ $\mathrm{ml}$. The present study is a retrospective analysis of anti Hbstitres among health care persons working in clinical laboratory which includes Microbiology, Pathology, Biochemistry and phlebotomy. Various studies have shown that prevalence of non responsiveness to the initial 3 dose regimen ranges between 10 and $15 \%{ }^{5}$.

The present study aims to analyze anti $\mathrm{Hbs}$ titres and immune response among health care workers (HCW) of clinical laboratory. The tas is to determine antibody levels against hepatitis $B$ virus and to analyze the immune response with respect to immunization among the health care workers.

\section{Methodology}

A retrospective analysis of antiHbs titres among health care personnel working in the clinical laboratory which includes Microbiology, Pathology, Biochemistry and phlebotomy was done. The data obtained following blood collection and ELISA performed by using a kit manufactured by Dia Pro Diagnostics, Bio probe Italy for quantitation of antibody titers was analysed. Vaccination history of the health care workers were recorded.

\section{RESULTS}

In the present study the antibody titres of 56 participants which includes doctors, lab technicians, phlebotomists, andhouse keeping from the department of Pathology, Microbiology,
Biochemistry were analysed. Antibody titers were measured by ELISA. Titers of $10 \mathrm{mIU} /$ $\mathrm{ml}$ was considered protective. Among the 56 participants $28(50 \%)$ were doctors, $17(30 \%)$ were lab technicians, $4(7.5 \%)$ were phlebotomists, $7(12.5)$ from housekeeping as shown in Table 1. 41 out of 56 had received all the three doses of Hepatitis B vaccine. 5 had received only 2 doses and 10 did not receive even a single dose of the vaccine. It was observed that 41 participants who received complete vaccination and 5 who received only 2 doses had protective levels of antiHbs titres (>10Mlunits $/ \mathrm{ml}$ ) (Table 2). Among the 10 participants who did not receive vaccination, 6 did not have protective titres but 4 had titres in the protective range.

Table 1. Shows the professional category of Health care workers

\begin{tabular}{ll}
\hline Doctor & $28(50 \%)$ \\
Lab technicians & $17(30 \%)$ \\
Phlebotomists & $4(7.5 \%)$ \\
House Keeping & $7(12.5)$ \\
\hline
\end{tabular}

Table 2. Shows the percentage of Healthcare workers with protective levels of Antibody titres following vaccination

\begin{tabular}{lccc}
\hline $\begin{array}{l}\text { Vaccination } \\
\text { status }\end{array}$ & Number & $\begin{array}{c}>10 \mathrm{MIU} / \\
\mathrm{ml}\end{array}$ & $\begin{array}{c}<10 \mathrm{MI} / \mathrm{ml} \\
\text { unit }\end{array}$ \\
\hline 3 Doses $(0,1,6)$ & $41(73.2 \%)$ & $41(73.2 \%)$ & $\mathrm{Nil}$ \\
2 Doses $(0,1)$ & $5(8.9 \%)$ & $5(8.9 \%)$ & $\mathrm{Nil}$ \\
Not & $10(17 \%)$ & $4(7.1 \%)$ & $6(10.7 \%)$ \\
Vaccinated & & & \\
\hline
\end{tabular}

\section{DISCUSSION}

Occupational exposure remains one of the main risk factors for $\mathrm{HCW}$ acquiring Hepatitis B infection ${ }^{6}$. In order to prevent this it becomes mandatory to be vaccinated with 3 doses of Hepatitis B vaccine and to get the anti $\mathrm{Hbs} \mathrm{Ag}$ titres checked after 2 months after completion of vaccine as per OSHA (Occupational Health and Safety Administration).

Hepatitis B vaccine induces antibody production against the surface antigen which is protective. In our study we found that all the participants who were completely vaccinated had protective levels of antiHbs antibody titres 
$(>10 \mathrm{ml} / \mathrm{ml})$, in contrast to studies conducted by Osmania medical college which shows $6.5 \%$ of completely vaccinated individuals with no protective antibody levels. Out of $10(17 \%)$ who were not vaccinated, $4(7.1 \%)$ had protective antibody titres which can be attributed to exposure to Hepatitis B virus from clinical specimen and sero conversion. Jeyalakshmi ${ }^{7}$ et al reported that $20 \%$ had protective titres in non vaccinated population which was higher when compared to what was observed in our study. In contrast, Chakraborthy et al. reported that antibody titres in non vaccinated individual were $<10 \mathrm{Ml}$ units $/ \mathrm{ml}$ in $100 \%$ of his study population. In our study we did not find any non responders following full course of Hepatitis $B$ vaccine. All of the participants in our study were vaccinated 1year back with Engerix B.

In the process of our analysis we identified the non vaccinated individuals and recommended vaccination for them. We also found that there was good antibody response in participants who had taken only 2 doses of vaccine. We educated the HCWs with regards to complete immunization against Hepatitis $B$ virus and the need to know their antibody titres following vaccination.

\section{CONCLUSION}

The efficacy of Hepatitis B vaccine is good and it is a safe vaccine. The government of India has included this vaccine in the National Immunisation Schedule. Health care workers are proned for needle stick injuries and exposure to hepatitis $B$ virus hence it is mandatory for all the Health care workers to get vaccinated and get their antiHbS titres checked once in 5 years. Its mandatory to administer booster dose of the vaccine in case of decrease in levels of antiHbS titres. It should be noted that lack of antibody response upon full course of Hepatitis $B$ vaccines should be considered as non responders. Non responsiveness to Hepatitis $B$ vaccine is attributed to genetic factors, smoking and obesity.

It is been associated with haplotypes of Human Leucocyte Antigens (HLA) of individuals who are poor responders. There is a need for analysis of these factors and screening for Hepatitis $B$ surface antigen periodically among the non responders.
Further the limitation of our study is lack of evaluation of risk factors liking smoking, nutritional status and alcoholism as these factors influences immune response.

\section{ACKNOWLEDGEMENTS}

None.

\section{CONFLICTS OF INTEREST}

All authors approved the final version of the manuscript and declare that they have no conflicts of interests.

\section{AUTHORS' CONTRIBUTION}

All authors have made substantial, direct and intellectual contribution to the work and approved it for publication.

\section{FUNDING}

None.

\section{DATA AVAILABILITY}

All datasets generated or analyzed during this study are included in the manuscript and/or the Supplementary Files.

\section{ETHICS STATEMENT}

Ethical clearance was obtained from Institutional Ethical Committee

\section{REFERENCES}

1. Joshi N., Kumar, Sreenivas D.V., Palan S., Nagarjuna Kumar Y.R., Safety and immunogenicity of indigenous recombinant hepatitis $B$ vaccine (Shanvac- $B$ ) in comparison with commercially available vaccine. Indian J. gastroenterol, 2000; 19(2): 71-3. PMD: 1081819.

2. ManishDwivedi, Sri Prakash Misra, VatsalaMisra, ArivindPndey, Sanjay Pant, Rita Singh \& M Anju Verma. Seroprevalence of hepatitis B infection during pregnancy and risk of perinatal transmission. Indian J. Gastronenterol, 2011; 30(2): 66-71.

3. Immunization of health-care personnel: Recommendations of the Advisory Committee on Immunization Practices (ACIP). MMWR RecommRp., 2011; 60(RR-7): 1-45.

4. Bidhan Chakraborty, Tanvir Bashar, Konok Roy, Rashed Noor, M Majibur Rahman. Persistence of Anti-HBs Antibody and Immunological Memory in Healthy Individuals Vaccinated with Hepatitis B Vaccine. Stamford Journal of Microbiology, 2011; 1: 37- 47.

5. Rao T.V., Suseela I.J., Sathaiavthy K.A. Estimation of antibodies to $\mathrm{HBsAg}$ in vaccinated health care workers. 
Indian J. Med. Microbiol., 2008; 26(6): 93-4.

6. Gopalakrishna R., Ramamurthy R. Sero-prevalence of Hepatitis B Infection among Health care workers and the importance of Anti Hbs testing among the Health care workers. Int. J. Curr. Microbiol. App. Sci., 2017; 6: $2280-85$.
7. Lakshmi J., Alekya P., Sasikala G. AntiHbs titres in health care persons of clinical laboratory. IOSR Journal of Dental and Medical Sciences, 2017; 16: 54-55. 